\title{
Korelasi Pengetahuan Mahasiswa Tentang Pemanasan Global Terhadap Perilaku Peduli Lingkungan Sekitar
}

\author{
Wahyu Septa Nugroho'1, Ismail², Anif Rizqianti Hariz ${ }^{3}$ \\ Program Studi Pendidikan Biologi, Fakultas Sains dan Teknologi, UIN Walisongo \\ Email: ${ }^{1}$ septa1994@gmail.com,2ismail@walisongo.ac.id, ${ }^{3}$ anifrizqianti@walisongo.ac.id
}

\begin{abstract}
Abstrak
Kehidupan manusia tidak dapat dipisahkan dari lingkungannya. Ada tidaknya masalah lingkungan tergantung bagaimana sikap dan tanggung jawab manusia terhadap lingkungannya. Penelitian ini bertujuan untuk mengetahui seberapa besar pengaruh pengetahuan tentang pemanasan global terhadap perilaku peduli lingkungan sekitar, dilakukan pada mahasiswa Pendidikan Biologi, Fakultas Sains dan Teknologi, UIN Walisongo. Diperoleh hasil bahwa pengetahuan pemanasan global tidak mempengaruhi secara signifikan perilaku peduli lingkungan sekitar. Pada umumnya perilaku peduli lingkungan sudah baik yaitu sebesar $62 \%$ dan pengetahuan tentang pemanasan global sudah cukup baik yaitu sekitar $75 \%$. Dari analisis data diperoleh hasil perhitungan adalah $r=0,125$ memberikan penafsiran bahwa tingkat pengaruh variabel sangat rendah. Kemudian diuji keberartian koefisien korelasinya dan didapat hasil berdasarkan perhitungan diperoleh bahwa thitung $=0,896$ untuk x dan y. Harga ini dikonsultasikan dengan $d k=52$ dan taraf signifikansi $5 \%$ diperoleh $t_{\text {tabel }}=2,009$. Karena $t_{\text {hitung }}<t_{\text {tabel }}$ maka $\mathrm{H}_{\mathrm{o}}$ diterima artinya tidak terdapat pengaruh yang signifikan antara pengetahuan tentang pemanasan global terhadap perilaku peduli lingkungan. Kemudian dihitung Koefisien Determinasi Pada Regresi Linier Sederhana. Didapat hasil bahwa Nilai koefisien determinasi $r^{2}=0,125^{2}=0,016$. Ini berarti bahwa pengaruh pengetahuan pemanasan global $(\mathrm{X})$ terhadap sikap peduli lingkungan(Y) sebesar 1,6\% terhadap perilaku peduli lingkungan. Selain dipengaruhi pengetahuan tentang pemanasan global juga dipengaruhi faktor lain sebesar 98,4\% yang tidak dijelaskan dalam penelitian ini.
\end{abstract}

Kata kunci: pemanasan global, perilaku peduli lingkungan, mahasiswa.

\section{Pendahuluan}

Negara Kesatuan Republik Indonesia (NKRI) merupakan negara yang terdiri dari ribuan pulau. Setiap pulau memiliki karakteristik masing-masing baik dari bidang ekonomi, sosial maupun budaya. Selain itu, kekayaan NKRI dapat dikaji dari sumber daya alamnya. Berdasarkan sumber daya alamnya, Indonesia memiliki berbagai macam hasil tambang, pertanian maupun perkebunan. Sumber daya alam tersebut dimanfaatkan untuk memenuhi kebutuhan hidup manusia. Akan tetapi, manusia sebagai homo economics melakukan eksploitasi pada sumber daya alam yang ada sehingga mengakibatkan terjadinya kerusakan dan pencemaran lingkungan.
Ada dua penyebab terjadinya kerusakan dan pencemaran lingkungan. Pertama, yang disebabkan oleh ulah manusia dengan sadar atau tidak sadar, langsung maupun tidak langsung mengakibatkan rusaknya lingkungan misalnya penggalian tanah pasir atau batu-batuan yang mengandung risiko tanah longsor dan penebangan pohon tanpa penanaman kembali. Kemudian yang kedua, kerusakan lingkungan yang disebabkan oleh faktor alam seperti petir, hujan yang lebat, angin tornado, dan musim kering (Dwijoseputro, 2003).

Pemanasan global merupakan salah satu indikator kerusakan alam yang disebabkan oleh ulah tangan manusia baik disengaja maupun tidak disengaja. Pemanasan global telah menjadi isu internasional sejak beberapa dekade belakangan ini 
bagi sebagian orang. Dampak dari pemanasan global antara lain semakin meningkatnya permukaan air dan semakin bertambah panas suhu di bumi ini. Disadari atau tidak, perbuatan yang dilakukan dapat merusak tatanan kehidupan misalnya saja membuang sampah sembarangan, penebangan pohon secara tidak aturan ataupun pemakaian bahan bakar fosil secara tidak efisien. Di antara keprihatinan yang semakin tinggi tentang betapa jahatnya manusia merusak lingkungan alamiah secara terus-menerus, mudah sekali ditemukan rasa pesimis tentang seberapa besar niatan manusia bersedia menjaga alam. Masih banyak orang yang menyia-nyiakan energi, menghabiskan sumber daya alam dengan cara-cara yang tidak lestari, merusak sistem-sistem pendukung kehidupan dan mencemari lingkungan (Meyr, 2009). Tampaknya manusia harus diancam, ditekan dan dihukum lebih dulu agar mau terlibat dalam perilaku pro lingkungan, seperti yang terdapat dalam surat QS Ar Rum ayat 41 Allah berfirman:

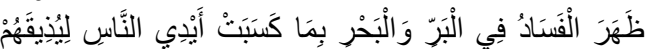

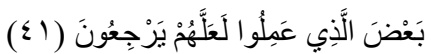

“Telah tampak kerusakan di darat dan di laut disebabkan karena perbuatan tangan manusia, Allah menghendaki agar mereka merasakan sebagian dari (akibat) perbuatan mereka, agar mereka kembali (ke jalan yang benar)".

Ayat tersebut menjelaskan bahwa sesungguhnya, kerusakan lingkungan di bumi, sebagian besar adalah kesalahan manusia. Manusia terlalu mengeksploitasi hasil alam sehingga merusak lingkungan (Al Maraghi, 1992). Meski sebenarnya manusia memang masih punya sedikit kepedulian terhadap alam, terbukti dari rating tertinggi foto, gambar atau lukisan berupa pemandangan alam mereka pilih sebagai hiasan dinding (Meyr, 2009).

Manusia, seperti halnya semua mahluk hidup berinteraksi dengan lingkungan hidupnya.
Begitu pula lingkungan hidup dipengaruhi oleh adanya aktivitas dari manusia (Soemarwoto, 2007).

Manusia sebagai khalifah di bumi memiliki peranan besar dalam menentukan kelestarian lingkungan hidup. Manusia sebagai mahluk ciptaan Tuhan yang berakal budi akan mampu merubah wajah dunia dari pola kehidupan sederhana sampai ke bentuk kehidupan yang modern (Ridwan, 2013). Perubahan perilaku manusia dapat merubah pola lingkungan hidup dan perubahan pola lingkungan dapat merubah perilaku manusia untuk menyesuaikan lingkungannya. Hal tersebut berarti bahwa manusia yang berperilaku baik terhadap lingkungan akan membentuk lingkungan hidup yang baik pula dan manusia yang berperilaku merusak akan menurunkan kualitas lingkungan hidup di sekitarnya. Namun sangat disayangkan jika seseorang yang sudah memiliki pengetahuan yang lebih tetapi tidak diterapkan pada lingkungan sekitarnya.

Mahasiswa yang mempunyai semboyan agent of change atau pembawa perubahan bagi sekitarnya, diharapkan mampu memberikan perubahan yang positif bagi masyarakat di sekitarnya. Akan tetapi di sisi lain masih ada yang kurang peduli pada lingkungan di sekitarnya. Misalnya saja masih ada yang suka membuang sampah sembarangan, menggunakan sumberdaya alam secara tidak lestari. Padahal di bangku perkuliahan khususnya pada Prodi Pendidikan Biologi UIN Walisongo Semarang sudah diberikan edukasi mengenai pengetahuan lingkungan dan konservasi sumber daya alam, yang di dalamnya membahas mengenai masalah-masalah yang terjadi di lingkungan sekitar misalnya pencemaran, kerusakan-kerusakan lingkungan dan cara mengurangi dampak dari kerusakan lingkungan. Diharapkan dengan pengetahuan tersebut Mahasiswa memiliki perilaku peduli terhadap lingkungan. Perilaku peduli terhadap lingkungan dapat ditunjukan antara lain dengan menggunakan 
energi secara efisien, menerapkan prinsip 3R (reduce, reuse, recycle).

Tujuan dilakukan penelitian ini adalah untuk mengetahui bagaimana pengetahuan mahasiswa Prodi Pendidikan Biologi UIN Walisongo Semarang tentang pemanasan global, bagaimana perilaku peduli lingkungan mahasiswa Prodi Pendidikan Biologi UIN Walisongo Semarang pada lingkungan sekitar, dan bagaimana pengaruh pengetahuan mahasiswa Prodi Pendidikan Biologi tentang pemanasan global terhadap perilaku peduli lingkungan sekitar di UIN Walisongo Semarang.

\section{Metode}

Penelitian dilakukan pada tahun 2016 pada mahasiswa Prodi Pendidikan Biologi, Fakultas Sains dan Teknologi UIN Walisongo Semarang angkatan 2013-2014 sebanyak 52 mahasiswa. Pemilihan objek penelitian berdasarkan pertimbangan mahasiswa yang telah mendapatkan dan lulus mata kuliah Konservasi Sumber Daya Alam. Pengambilan data menggunakan tes untuk mengetahui seberapa jauh pengetahuan mengenai pemanasan global serta wawancara menggunakan angket untuk mengetahui bagaimana sikap peduli lingkungan yang telah diaplikasikan dalam kehidupan seharihari.

\section{Hasil dan Pembahasan}

Pengetahuan merupakan sesuatu yang ada pada diri manusia. Keberadaannya diawali dari kecenderungan psikis manusia yaitu adanya dorongan rasa ingin tahu yang bersumber dari kehendak atau kemauan (Suhartono, 2005). Dalam proses belajar pembelajaran setiap individu memiliki kemampuan yang berbeda-beda dalam memahami yang telah dipelajari. Ada yang memahami secara menyeluruh adapula yang sama sekali tidak dapat mengambil makna dari pembelajaran. Pengetahuan dapat diperoleh dari jalur formal dan jalur non formal. Mahasiswa Prodi Pendidikan Biologi angkatan 2013-2014 secara umum sangatlah heterogen dalam hal pengetahuan tentang pemanasan global. Pengetahuan tentang pemanasan global diperoleh dari jalur tersebut.

Perhitungan skor tes pengetahuan pemanasan global diketahui rata-rata persentasenya adalah 75\%, menunjukkan bahwa mahasiswa Prodi Pendidikan Biologi angkatan 2013-2014 UIN Walisongo Semarang memiliki kategori pengetahuan pemanasan global yang "cukup". Dengan memiliki kategori cukup tersebut artinya mahasiswa mampu dalam:

a. Menjelaskan pengertian pemanasan global

b. Mengidentifikasi dampak pemanasan global terhadap lingkungan

c. Mengidentifikasi penyebab pemanasan global

d. Menjelaskan bagaimana cara mengurangi terjadinya pemanasan global.

e. Menjelaskan tentang tanggung jawab manusia terhadap lingkungan.

Hasil penelitian pengetahuan tentang pemanasan global pada mahasiswa Prodi Pendidikan Biologi angkatan 2013-2014 diperoleh rata-rata persentasenya adalah $75 \%$. Dengan rincian bahwa $57 \%$ mahasiswa memiliki kategori baik yaitu sebanyak 30 mahasiswa, 38\% memiliki kategori cukup yaitu sebanyak 21 mahasiswa dan $2 \%$ mahasiswa memiliki kategori yang kurang yaitu sebanyak 2 mahasiswa.

Perilaku adalah segala sesuatu yang dilakukan oleh manusia atau hewan yang dapat diamati dengan cara tertentu (Khadijah, 2014). Berdasarkan penelitian yang telah dilakukan melalui angket, ada mahasiswa yang kurang peduli terhadap lingkungan. Dibuktikan dengan perhitungan skor angket perilaku peduli lingkungan diketahui rata-rata persentasenya $62 \%$ yang menunjukan bahwa mahasiswa Prodi Pendidikan Biologi angkatan 2013-2014 UIN Walisongo Semarang memiliki kategori yang "cukup". Dengan rincian 8\% mahasiswa memiliki kategori baik yaitu sebanyak 4 mahasiswa, 88\% mahasiswa memiliki kategori cukup yaitu sebanyak 46 mahasiswa, 2\% memiliki kategori kurang dan 2\% memiliki kategori sangat kurang masing-masing sebanyak 1 
mahasiswa. Berdasarkan rata-rata persentase tersebut dapat dikategorikan bahwa mahasiswa prodi pendidikan biologi angkatan 2013-2014 UIN Walisongo Semarang memiliki kategori yang "cukup". Dengan kategori tersebut mahasiswa diharapkan berperilaku sebagai berikut:

a. Mempengaruhi orang lain agar peduli terhadap lingkungan

b. Merawat tanaman disekitar lingkungannya.

c. Mengaplikasikan perilaku 3R guna mengurangi dampak pemanasan global.

d. Menggunakan sarana dan prasarana yang ramah lingkungan.

Data-data tersebut diperoleh dari instrumen tes dan kuesioner yang diolah menggunakan metode statistik yang telah ditentukan, sehingga ditemukan hasil akhir yang menentukan apakah hipotesis akhir penelitian ini diterima atau diolak. Berdasarkan analisis regresi tersebut menunjukan bahwa pengetahuan mahasiswa tentang pemanasan global (variabel $\mathrm{x}$ ) tidak memiliki pengaruh yang signifikan terhadap perilaku peduli lingkungan (variabel y). Artinya pengetahuan mahasiswa tentang pemanasan global tidak memberikan konstribusi yang signifikan terhadap perilaku peduli lingkungan. Hal ini di buktikan dengan persamaan regresinya yaitu $y=45,444+$ 0,511x. Menunjukan bahwa perilaku peduli lingkungan sekitar tidak hanya dipengaruhi oleh pengetahuan tentang pemanasan global. Akan tetapi dipengaruhi oleh faktor lain yang tidak dijelaskan dalam penelitian ini. Hal ini dibuktikan dalam perhitungan koefisien determinasiya, bahwa pengetahuan tentang pemanasan global hanya menyumbang sekitar 1,6\% dan 85\% dipengaruhi oleh faktor lain. Tetapi jika dilihat dari Fhitung menunjukkan bahwa $\mathrm{H}_{\mathrm{o}}$ diterima dan $\mathrm{H}_{\mathrm{a}}$ ditolak. Menyatakan bahwa tidak ada pengaruh yang signifikan pengetahuan tentang pemanasan global terhadap perilaku peduli lingkungan sekitar.

\section{Kesimpulan}

Mahasiswa Pendidikan Biologi UIN Walisongo Semarang diketahui 57\% memiliki kategori baik, 38\% memiliki kategori cukup, dan
2\% memiliki kategori kurang dalam hal pengetahuan mengenai pemanasan global. Dari perilaku peduli lingkungan yang telah dilakukan sebanyak 8\% memiliki kategori baik, 88\% cukup, $2 \%$ kurang, dan 2\% sangat kurang. Perilaku mahasiswa yang ditunjukkan ternyata tidak dipengaruhi secara signifikan oleh pengetahuannya tentang pemanasan global dan justru dipengaruhi sangat kuat oleh faktor-faktor lainnya yang tidak dijelaskan dalam penelitian ini.

\section{Daftar Pustaka}

Achmad, Rukaesih. 2007. Kimia Lingkungan. Andi Offset. Yogyakarta.

Arikunto, Suharsimi. 2013. Prosedur Penelitian Suatu Pendekatan Praktik. Rineka Cipta. Jakarta.

Azwar S. 2003. Sikap Manusia Teori dan Pengukurannnya. Pustaka Pelajar. Yogyakarta.

Clayton, S. dan Meyr. G. 2009. Psikologi Konservasi. Terjemahan Daryatno. Pustaka Pelajar. Yogyakarta.

Dwidjoseputro. 2003. Ekologi Manusia dengan Lingkungannya. Erlangga. Jakarta.

Hamzah, Ibnu. 2013. Implementasi Bahan Ajar IPA Terpadu Konsep Pemanasan Global Kelas VII di MTS NU Rudlatul Muallimin. Unnes. Semarang.

Keraf, Sonny. 2010. Etika Lingkungan. PT. Kompas Media Nusantara. Jakarta.

Khadijah, Nyayu. 2014. Psikologi Pendidikan. Rajawali Pers. Jakarta.

Kumurur, Veronica A. 2008. Pengetahuan, Sikap dan Kepedulian Mahasiswa Pasca Sarjana Ilmu Lingkungan Terhadap Lingkungan Hidup Kota Jakarta. Vol. 8.

Margono. 2010. Metodologi Penelitian Pendidikan. Rineka Cipta. Jakarta.

Musthafa, Ahmad al Maraghi. 1992. Terjemah Tafsir al-Maraghi jilid 21. PT. Karya Toha Putra. Semarang.

Nugraha, Adrian R. 2013. Pemanasan Global dan Dampaknya. PT. Gading Inti Prima. Jakarta. 
Putra, M. Adeeva. 2013. Global Warming Mengancam Bumi Kita. Mitra Sarana. Bandung.

Ramly, Nadjmuddin. 2005. Membangun Lingkungan Hidup yang Harmonis \& Berperadaban. Grafindo Khazanah Ilmu. Jakarta.

Riduwan dan Sunarto. 2013. Pengantar Statistika untuk Penelitian: Pendidikan, Sosial, Komunikasi, Ekonomi, dan Bisnis. ALFABETA. Bandung.

Riduwan. 2010. Dasar-Dasar Statistika. Alfabeta. Bandung.

Ridwan, Iwan. 2013. Melestarikan Lingkungan Biotik dan Abiotik. Pustaka Setia. Bandung.

Rusbiyanto, Dadang. 2008. Global Warming for Beginner. 02. Yogyakarta.

Saefulhadi, Bambang. 2009, Pengaruh Pendidikan Kependudukan dan Lingkungan Hidup Terhadap Perilaku Peduli Lingkungan. Skipsi. UNY. Yogyakarta.

Setianingsih. 2004. Studi Komparasi Pemeliharaan Lingkungan Hidup Antara Agama Islam dan Agama Kristen. Skripsi. IAIN Walisongo. Semarang.

Setiawan. 2014. Pencegah Pemanasan Global. Aryhaeko Sinergi Pustaka. Surakarta.

Soemarwoto, Otto. 2007. Ekologi Lingkungan Hidup dan Pembangunan. Djambatan. Bandung.

2007. Analisis Mengenai Dampak Lingkungan. UGM Press. Yogyakarta.
Subana. dkk. 2000. Statistik Pendidikan. Pustaka Setia. Bandung.

Sudjana. 2002. Metoda Statistika. Tarsito. Bandung.

Sugiarto, dkk. 2001. Teknik Sampling. PT Gramedia Pustaka Utama. Jakarta.

Sugiyono. 2010. Metode Penelitian pendidikan (pendekatan kuantitatif, kualitatif dan R \& D). CV. Alfabeta. Bandung,.

2012. Metode Penelitian pendidikan (pendekatan kuantitatif, kualitatif dan R \& D). CV. Alfabeta. Bandung.

Suhartono, Suparlan. 2005. Filsafat Ilmu Pengetahuan. AR-RUZZ. Yogyakarta.

Sukardi. 2009. Metodologi Penilitian Pendidikan: Kompetensi dan Praktiknya. PT. Bumi Aksara. Jakarta.

Supardi, Imam. 2003. Lingkungan Hidup dan Kelestariannya. PT. ALUMNI. Bandung.

Taufik Mohammad. 2010. Asal-usul pengetahuan dan hakikat pengetahuan. Bogor : IPB

Waryono, Taerson. 2008. Upaya Pemberdayaan Masyarakat dalam Pelestarian Hutan Sebagai Upaya Pencegahan Pemanasan Global Vol. 4.

Yuliawati, Fitri. 2011. Uji Kompetensi Biologi Untuk SMP. Pustaka Pelajar. Yogyakarta.

Tim Penyusun Kamus Pusat Bahasa. 2005. Kamus Besar Bahasa Indonesia. Balai Pustaka. Jakarta. 